\title{
RESENHA:
}

\section{UM ARTÍFICE}

NA URBANIZAÇÃO

\section{PAULISTANA:}

RIZKALLAH JORGE TAHAN (1895 - 1949).

ALMEIDA, RENATA GERAISSATI CASTRO DE.

SÃO PAULO: ANNABLUME, 2018. 224 P.

LUIS FERNANDO SIMÕES MORAES, UNIVERSIDADE FEDERAL DE SÃO PAULO, SÃO PAULO, SÃO PAULO, BRASIL

Historiador graduado pela Universidade Federal de São Paulo. Mestrando em História pela mesma instituição. Servidor Técnico Administrativo da Universidade de São Paulo e membro do grupo de pesquisa Cidade, Arquitetura e Preservação em Perspectiva Histórica, da Universidade Federal de São Paulo.

Orcid: https://orcid.org/0000-0002-0581-3305

E-mail: Ifsmoraes@gmail.com

\section{DOI:}

25/09/2020

APROVADO

http://doi.org/10.11606/issn.1980-4466.v16i31p391-398 
RESENHA: UM ARTÍFICE NA URBANIZAÇÃO

PAULISTANA: RIZKALLAH JORGE TAHAN (1895 - 1949)

ALMEIDA, RENATA GERAISSATI CASTRO DE.

SÃO PAULO: ANNABLUME, 2018. 224 P.

LUIS FERNANDO SIMÕES MORAES

A ampliação da escala sobre o objeto de estudo tem sido tarefa bastante empreendida por historiadores durante os últimos anos. A técnica consiste na análise do micro para se chegar ao entendimento do macro, observando de perto nuances que poderiam passar despercebidas dentro de determinados processos históricos. Essas diferentes escalas, para Giovanni Levi (MONTEIRO, 2008), são constituintes da mesma história geral, pois a micro-história parte de problemas macro-históricos e enxerga na escala micro a chance de analisar esses problemas a partir da observação de mecanismos não alcançados pela escala macro.

Quando nos debruçamos sobre os estudos referentes aos espaços urbanos, a redução da perspectiva de análise pode gerar bons resultados, pois as cidades são artefatos produzidos pela ação humana, por meio de sua interação com o meio físico. Diante disso, conforme nos diz Richard Morse (1995), "as cidades tornam-se teatros e nossos informantes, atores" (p. 205).

Nesse sentido, se nos ativermos à abordagem do complexo período vivenciado pela cidade de São Paulo entre os anos finais do século XIX e as primeiras décadas do XX, o ajuste na escala para uma visualização "mais de perto" pode nos ajudar na compreensão dos processos históricos, assim como a fugir de lugares-comuns recorrentes na historiografia.

E é sob tal perspectiva que a historiadora Renata Geraissati de Almeida, em Um artífice na urbanização paulistana: Rizkallah Jorge Tahan (1895-1949), analisa a trajetória de vida do artífice, empresário e investidor sírio-libanês Rizkallah Jorge Tahan (1869-1949), situando sua atuação dentro do contexto histórico da urbanização de São Paulo, tendo como recorte o ano de sua chegada à cidade, ocorrida em 1895, até sua morte, em 1949. 
Fruto da dissertação de mestrado da autora, concluída em 2016 e apresentada ao Programa de Pós-Graduação em História da Universidade Federal de São Paulo (Unifesp), a obra está dividida em três capítulos, em que Almeida perpassa a biografia desse "personagem", a relação de seus negócios com o crescimento e as mudanças provocadas pelo intenso processo de urbanização na cidade até chegar às apropriações da imagem de Rizkallah dentro da cidade que o acolheu.

As fontes utilizadas consistem em documentos textuais e iconográficos, em especial plantas e documentos pessoais, pesquisados principalmente no acervo da Casa da Boia, antiga loja e fábrica de produtos sanitários da cidade de São Paulo e principal negócio de Rizkallah. Essa documentação é mantida por Mario Rizkallah, neto do empresário e atual proprietário da Casa da Boia. Outros documentos também foram pesquisados no Arquivo Geral da Prefeitura Municipal de São Paulo e no Arquivo Histórico Municipal de São Paulo, além de jornais, sítios eletrônicos governamentais e outras publicações impressas.

A partir da documentação encontrada, no capítulo inicial, denominado Do navio à tubulação, são tratadas as origens e trajetória de Rizkallah, apontando sua formação e trajetória profissional antes mesmo de chegar ao Brasil e o quanto isso teve influência em suas atividades aqui desempenhadas. Nascido em 1869 em Alepo, cidade localizada na Síria, Rizkallah imigrou para o Brasil em 1895. Ao contrário da maioria de seus patrícios, que inicialmente se envolviam com a comercialização de tecidos e outros produtos como "mascates", procurou trabalhar no mesmo ramo que desenvolvia na terra natal: a fundição de cobre - ofício que aprendeu com seu pai. Encontrando emprego como faxineiro numa loja de metais importados na rua Florêncio de Abreu, após três anos se tornou seu proprietário, fundando a Rizkallah Jorge e Cia no dia 20 de maio de 1898.

Ainda no primeiro capítulo, a autora contextualiza a imigração sírio-libanesa, demonstrando que grande parte de seus integrantes acabou se estabelecendo principalmente no meio urbano. No entanto, conforme mencionado anteriormente, Rizkallah não seguiu a profissão de mascate, como muitos de seus conterrâneos, buscando se firmar num trabalho em que já possuía formação. 
Possuindo origens sírio-libanesa e armênia, ${ }^{1}$ nosso personagem também foi membro ativo e influente de ambas as comunidades, atuando como benemérito. Dentre suas benfeitorias, se destacam as ajudas a imigrantes recém-chegados ao Brasil e as doações, de dinheiro para a construção da igreja de São Jorge para a comunidade armênia; e de um aeroplano para o aeroclube de São Paulo. Consolidando, então, suas redes, Rizkallah também foi integrante do Clube Syrio, importante agremiação da colônia, além de ter envolvimento na construção do Hospital Syrio.

As realizações apontadas, antes de serem tratadas como atos de simples boa vontade (por mais que ela pudesse existir), não deixam de ser problematizados pela autora, que, ao refletir sobre tais ações, conclui que consistem na formação de um poder simbólico (BOURDIEU, 1992), de que o imigrante pode ter feito uso para obtenção de benefícios em suas atividades políticas e financeiras.

Partindo para o segundo capítulo, A boia, o tijolo e o concreto armado, esse desenvolvimento, tanto do capital financeiro quanto simbólico de Rizkallah, é melhor trabalhado. Nessa etapa, Almeida demonstra o quanto a ascensão dos negócios do imigrante está intrinsecamente ligada às transformações urbanas pelas quais São Paulo passava.

Chegando à cidade num momento de profundas reformulações (e expansão) urbanas, quando ocorria uma profusão de estudos científicos, tanto no Brasil quanto em outros países, sobre as condições sanitárias urbanas, o "saber fazer" de Rizkallah encontrou espaço garantido num lugar em que havia escassez de profissionais especializados na confecção de materiais como a boia sanitária, por ele fabricada, que passaram a ter suma importância nos ambientes domésticos.

Com a urbanização da cidade cada vez mais acelerada, a maneira como se deveria lidar com a água e a necessidade de construções higiênicas e salubres fizeram com que a demanda da Companhia, posteriormente "Casa da Boia", ${ }^{2}$ aumentasse. Era uma cidade que se pretendia moderna e, para isso, buscava se livrar da imagem arcaica de pessoas - escravos transportando em recipientes os dejetos pelas ruas. 
Dentre a documentação trabalhada pela autora, foram encontrados contratos de profissionais de origem inglesa e alemã, mão de obra especializada contratada pelo empresário, que visava o aprimoramento do desempenho da fábrica, agregando conhecimentos sobre a fundição de metais - tais profissionais, conforme os contratos analisados, tinham também como função ensinar os aprendizes da fábrica.

Para além do empreendimento da Casa da Boia, Rizkallah também aplicou seus capitais no setor imobiliário, construindo seus "palacetes", que consistiam, na prática, em prédios de apartamentos, tendo sido, dessa maneira, um dos promotores da verticalização da cidade.

Desde as décadas finais do século XIX, sobretudo após o fim da escravidão, o investimento em propriedades urbanas passou por grande valorização e, principalmente até a década de 1930, eram tidos como de "lucro certo", posto a demanda de uma classe "média" que se projetava.

Rizkallah entra nessa seara, portanto, com produtos que difundiam a coletivização da moradia, com os Palacetes São Jorge, Paraíso e Alepo, todos localizados nas proximidades da Casa da Boia e possuindo inquilinos pertencentes, em boa parte, às colônias médio-orientais presentes na cidade. A partir da análise das plantas dos edifícios, a autora demonstra o quanto é possível compreender a recepção dos discursos de salubridade no interior dos imóveis, o que propiciou a inserção dos banheiros dentro do espaço doméstico, possibilitando a difusão gradual do uso da boia sanitária, item responsável pela riqueza do imigrante.

Além dos imóveis, Rizkallah também realizou investimentos em importação e exportação (tabaco em folha, cartuchos para munições são alguns dos produtos descritos), se inserindo numa rede internacional de negócios, que ultrapassava as fronteiras internacionais. Grande parte do acervo da Casa da Boia é composto por recibos que contam com selos dos mais diversos bancos do mundo, como o National Bank of New York, London \& River Plate Bank, Royal Bank of Canada, além de outros.

A enumeração dos negócios do imigrante demonstra, naturalmente, um notável grau de ambição de alguém que chegou à cidade com recursos escassos, mas conseguiu conquistar fortuna. Ambição que, no entanto, não pode ser analisada apenas no que concerne à maximização dos lucros, mas, como no caso das construções, pode consistir numa resposta à pergunta de 
como seu enriquecimento foi visto na sociedade de São Paulo. Para pensar sobre essa questão, a autora usa como referência o estudo de Fernando Atique sobre o Edifício Esther, em São Paulo, afirmando que as construções erigidas podem ser vistas também como uma tentativa de impor um símbolo de riqueza no espaço urbano, tendo o imigrante seu poder vinculado a uma “corrida às alturas" em São Paulo (ATIQUE, 2004).

Diante disso, partimos para o terceiro capítulo, As apropriações da imagem do imigrante proeminente, em que é trabalhado como esse capital simbólico foi lapidado durante e após o período de vida de Rizkallah. Após sua morte, em 1949, foi iniciado em 1950 um projeto de lei, $\mathrm{n}^{\circ} 291$, da Câmara Municipal de São Paulo, que pretendia nomear parte da então Avenida Anhangabaú com o nome do imigrante. Esse processo foi montado contando com missivas das instituições das quais Rizkallah foi benemérito, como a Igreja Apostólica Armênia do Brasil, a Sociedade do Hospital Samaritano, a Sociedade Beneficente de Senhoras Mão Branca do pró-asilo à velhice, o Sanatório Syrio, entre várias outras. Tais apoios contaram também com listas de assinaturas de moradores e comerciantes da região, reivindicando a homenagem. Ou seja, as redes que o imigrante foi tecendo em vida, nesse momento passam a reivindicar uma memória que remeta a um de seus membros de maior proeminência, buscando se firmar no espaço do município.

No entanto, várias tramas permearam esse processo, posto que a Comissão de Educação e Cultura pretendia homenagear o ex-presidente do PRP Jorge Tibiriçá, resultando em uma disputa - tradição (nacional) X memória do estrangeiro. Por fim, o nome de Rizkallah foi dado a uma via sem nome que começava na Avenida Anhangabaú e terminava na Brigadeiro Tobias, em 1952.

A preservação da memória imigrante também se consubstanciou nos processos de tombamento/zoneamento da região Z8-200, em que se inserem as principais obras de Rizkallah (Casa da Boia e seus palacetes), protegidos pelo poder público municipal e listados no guia dos bens culturais do município de São Paulo pelo DPH, ou seja, se tornando monumentos históricos.

Almeida também enfatiza a preocupação com a preservação de uma memória empreendida pelo próprio Rizkallah, que em 1928 encomendou 
um vídeo à companhia Oriente Films, em que divulga não somente seus negócios (casa da boia, palacetes), como também seu ambiente doméstico, mostrando sua família na casa na Avenida Paulista. Indo ao encontro do que diz Michael Pollak em relação à necessidade de testemunhas oculares inscreverem suas experiências contra o esquecimento, a partir do momento em que se dão conta que irão desaparecer (POLLAK, 1989), a produção encomendada pelo imigrante, assemelhada a obras do expressionismo alemão, enquadra as gerações da família (filhos), o logotipo da empresa, o progresso, a presença ativa na cidade e a modernização (fábrica e imagens da cidade).

Mesmo após a morte, essa busca pela perpetuação da memória do imigrante que "fez a América" se encontra presente na arte tumular que compõe o jazigo em que Rizkallah foi sepultado, no cemitério da Consolação. Nela, há elementos que remetem à religiosidade cristã, ao trabalho, à família e às raízes e se encontram inscrições em árabe.

Concluída a análise, Almeida pontua que o estudo sobre a trajetória e atuação do imigrante em São Paulo não pretendeu traçar uma trajetória de vida "excepcional", que, dotada de grandes habilidades, "deu certo", mas enquadrar a personagem como um sujeito histórico atuando dentro de um determinado contexto, em que foi favorecido por diversos fatores, não lhe valendo uma determinada alcunha (podendo ser classificado como artífice, rentista, capitalista, investidor, imigrante etc.).

A partir da leitura dessa obra, fica demonstrado o quanto a ampliação da escala pode auxiliar o trabalho do historiador na compreensão de complexos processos históricos, tendo como ênfase a agência dos indivíduos e as redes de sociabilidades por eles desenvolvidas. Além disso, propicia a desconstrução de generalizações, posto que a trajetória de imigrante de Rizkallah diferia do que comumente é colocado pela historiografia, pois, além de não ter seguido a mesma trajetória profissional de outros patrícios aqui presentes, foi um imigrante que aparentemente não pretendia simplesmente acumular dinheiro e retornar à terra natal. Ao contrário, buscou se fixar no país, aqui constituiu sua família e buscou firmar a sua "marca" no novo local.

Podemos concluir, portanto, que as análises feitas pela historiadora consistem numa valiosa contribuição para a história da imigração, 
relacionando-a com a produção do espaço construído da cidade. Sendo Rizkallah Jorge Tahan o detentor de um "saber fazer" que vinha ao encontro dos interesses urbanizadores do período em que prosperou economicamente, também foi uma figura que buscou consolidar sua identidade na cidade, o que demonstra, assim, o quanto a construção da "urbe" consiste em interesses e apropriações difusas, protagonizadas por seus agentes integrantes. E são esses aspectos que levantados e trabalhados por Almeida.

\section{REFERÊNCIAS}

ALMEIDA, Renata Geraissati Castro de. Um artífice da urbanização paulistana: Rizkallah Jorge Tahan (1895 - 1949). São Paulo: Annablume, 2018.

ATIQUE, Fernando. Memória moderna: a trajetória do Edifício Esther. São Carlos: RiMa/ Fapesp, 2004

BOURDIEU, Pierre. A economia das trocas simbólicas. São Paulo: Perspectiva, 1992.

MONTEIRO, Lívia Nascimento. Entre escolhas e incertezas: a utilização de abordagem micro-analítica na história social. Juiz de Fora: Clio, 2008.

MORSE, Richard. As cidades "periféricas" como arenas culturais: Rússia, Áustria, América Latina. Estudos Históricos, Rio de Janeiro, v.8 n. 16, 1995.

POLLAK, Michael. Memória, esquecimento, silêncio. Estudos Históricos, Rio de Janeiro, v.5, n.10, p. 200-212, 1989.

(9) $(1)(0)$ 